\title{
Kruppel-like factor 5 Controls Villus Formation and Initiation of Cytodifferentiation in the Embryonic Intestinal Epithelium
}

\author{
Sheila. M. Bell ${ }^{1}$, Liqian Zhang ${ }^{1}$, Yan $\mathrm{Xu}^{1}$, Valerie Besnard ${ }^{1}$, Susan E. Wert ${ }^{1}$, Noah Shroyer ${ }^{2}$, \\ and Jeffrey A. Whitsett ${ }^{1,{ }^{*}}$ \\ ${ }^{1}$ Perinatal Institute, Division of Neonatology-Perinatal-Pulmonary Biology, Cincinnati Children's \\ Hospital Medical Center, University of Cincinnati College of Medicine. 3333 Burnet Avenue, \\ Cincinnati, $\mathrm{OH} 45229$ \\ ${ }^{2}$ Perinatal Institute, Division of Gastroenterology, Cincinnati Children's Hospital Medical Center, \\ University of Cincinnati College of Medicine. 3333 Burnet Avenue, Cincinnati, $\mathrm{OH} 45229$
}

\begin{abstract}
Kruppel-like factor 5 (KIf5) is a transcription factor expressed by embryonic endodermal progenitors that form the lining of the gastrointestinal tract. A KIf 5 floxed allele was efficiently deleted from the intestinal epithelium by a Cre transgene under control of the $S h h$ promoter resulting in the inhibition of villus morphogenesis and epithelial differentiation. Although proliferation of the intestinal epithelium was maintained, the expression of Elf3, Ppary, Atoh1, Ascl2, Neurog3, Hnf4a, Cdx1, and other genes associated with epithelial cell differentiation was inhibited in the Klf5-deficient intestines. At E18.5, Klf5 $5^{\Delta / \Delta}$ fetuses lacked the apical brush border characteristic of enterocytes, and a loss of goblet and enteroendocrine cells was observed. The failure to form villi was not attributable to the absence of HH or PDGF signaling, known mediators of this developmental process. Klf5-deletion blocked the decrease in FoxA1 and Sox 9 expression that accompanies normal villus morphogenesis. KLF5 directly inhibited activity of the FoXA1 promoter, and in turn FOXA1 inhibited Elf3 gene expression in vitro, linking the observed loss of Elf3 with the persistent expression of FoxA1 observed in Klf5-deficient mice. Genetic network analysis identified KLF5 as a key transcription factor regulating intestinal cell differentiation and cell adhesion. These studies indicate a novel requirement for KLF5 to initiate morphogenesis of the early endoderm into a compartmentalized intestinal epithelium comprised of villi and terminally differentiated cells.
\end{abstract}

\section{Keywords}

Elf3; FoxA1; intestine development; cell adhesion

\section{INTRODUCTION}

The primitive endoderm forms the gut tube extending from the rostral to caudal ends of the embryo. Early patterning of the gut is defined along the proximal-distal axis by restricted

\footnotetext{
(C) 2012 Elsevier Inc. All rights reserved.

"Corresponding author: Dr. Jeffrey Whitsett, Cincinnati Children's Hospital Medical Center, Division of Pulmonary Biology, MLC 7029, 3333 Burnet Avenue, Cincinnati, OH 45229 USA. Phone: 1- 513-803-2790, Fax: 1-513-636-7868,

Jeffrey.Whitsett@cchmc.org.

Publisher's Disclaimer: This is a PDF file of an unedited manuscript that has been accepted for publication. As a service to our customers we are providing this early version of the manuscript. The manuscript will undergo copyediting, typesetting, and review of the resulting proof before it is published in its final citable form. Please note that during the production process errors may be discovered which could affect the content, and all legal disclaimers that apply to the journal pertain.
} 
patterns of transcription factor expression i.e. Sox 2 is restricted to the proximal regions that will develop into the esophagus and stomach (Raghoebir et al., 2012). $C d \times 2$ expression is restricted to more distal regions giving rise to the small intestine and colon (Gao et al., 2009). In contrast, other factors, including KIf5, FoxAl, and Sox 9 , are initially expressed along the entire length of the gastrointestinal tract (Bagheri-Fam et al., 2006; Besnard et al., 2004; Moore-Scott et al., 2007). Beginning on approximately embryonic day 14.5 of gestation (E14.5), the pseudostratified epithelium of the intestine transitions to a single layered columnar epithelium as villi begin to form. Villi are finger-like projections of terminally differentiated epithelium and supporting lamina propria that increase the luminal surface area of the intestine. Villus formation ensues between E15-E16.5 in the mouse, beginning proximally and proceeding distally. By E18.5, villi are present throughout the intestine and terminally differentiated absorptive (enterocyte) and secretory (goblet and neuroendocrine) cells are present. Between the villi is a highly proliferative intervillus region that will give rise to the crypts of Lieberkuhn, where stem cells reside in the mature organ (for review see, Spence et al., 2011). Many studies on intestinal maturation have focused on the role of the crypt in maintaining the villi and the epithelial cell types found in the mature intestine. Factors regulating the initial establishment of the villus are less well understood. In the present study, we identified an important role of Kruppel-like factor 5 (KIf5) in formation of the fetal intestine.

Klf5 is a member of a large family of transcription factors that share a characteristic $\mathrm{C}_{2} \mathrm{H}_{2}$ zinc-finger DNA binding domain. Klf5 is expressed in many tissues where it both activates and represses transcription of target genes(Dong and Chen, 2009). In embryonic stem cells, KLF5 plays an important role in self-renewal and maintenance of pluripotency (Nandan and Yang, 2009). During mouse embryogenesis, tissue specific deletion of Klf5 demonstrates its requirement for implantation (Sun et al., 2012), adipocyte differentiation (Oishi et al., 2005), bladder urothelial maturation (Bell et al., 2011), terminal maturation of lung epithelial cells (Wan et al., 2008), and postnatal- development of the eyelid and cornea (Kenchegowda et al., 2011). KIf 5 is highly expressed throughout development in the gastrointestinal epithelium (Dong and Chen, 2009). In the adult intestine, KLF5 co-localizes with highly proliferative cells within the crypt. A recent study by McConnell et al (2011) demonstrated that deletion of KLF5 in the postnatal intestinal epithelium disrupted crypt architecture and the balance between goblet and enteroendocrine cells within the colon. In the present study, we demonstrate that KLF5 also plays a pivotal role in establishing the villus in the fetal intestine prior to formation of the crypts. In the absence of villus formation, terminal maturation of small intestine and colonic cell types was inhibited by loss of KLF5.

\section{MATERIALS AND METHODS}

\section{Animals}

Animal protocols were approved by the Institutional Animal Care and Use Committee in

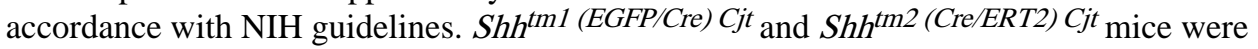
purchased from Jackson Laboratories (Bar Harbor, ME) and mated with KIffflox/flox animals (Harfe et al., 2004; Wan et al., 2008). Klf5 $5^{\text {flox/flox }}$ females were time mated to Klf5 ${ }^{\text {flox } / w t}$;

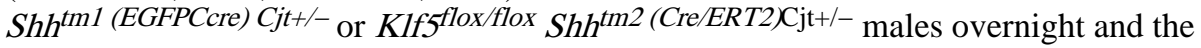
presence of a vaginal plug defined as embryonic day 0.5 (E0.5). Pregnant dams mated with $\mathrm{Shh}^{\mathrm{tm} 2 \text { (Cre/ERT2) }}$ males were gavaged on E13.5 with $200 \mu \mathrm{l}$ of a $20 \mathrm{mg} / \mathrm{ml}$ solution of tamoxifen made in corn oil. Genomic DNA isolated from fetal tails was used for PCR genotyping (Wan et al., 2008). 


\section{Immunohistochemistry}

Embryos were fixed in $4 \%$ paraformaldehyde $24-48 \mathrm{hrs}$ and embedded in either paraffin or OCT. Paraffin embedded tissue was sectioned at $6 \mu \mathrm{m}$ and frozen tissue was sectioned at 9 $\mu \mathrm{m}$. Immunohistochemistry was performed as previously described (Bell et al., 2011) using the primary antibodies as indicated in Supplementary Methods Table 1. At least three animals of each genotype were evaluated per time point.

\section{Intestinal length measurements}

Fetal small intestine lengths were measured from the beginning of the duodenum to the cecum and were normalized to the crown/rump length of each fetus at E14.5, E16.5 and E18.5.

\section{Quantitative Real-time PCR}

Total RNA was isolated from E14.5, E16.5, or E18.5 segments of the intestine, approximately $1.5 \mathrm{~cm}$ immediately anterior to the cecum, using the QIAGEN micro or mini

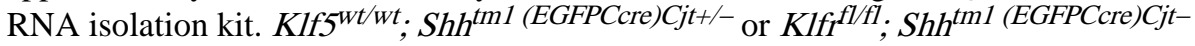
embryos were used for the control sample. CDNA samples were generated using the Versa RT-kit (ThermoScientific) and amplified in triplicate on a StepOne Plus Real Time PCR system (Applied Biosystems) using the Applied Biosystems TAQMAN primer pairslisted in Supplementary Methods Table 2. All values were normalized to ribosomal 18S RNA within the sample and values calculated using the $2^{-\Delta \Delta C T}$ method (Livak and Schmittgen, 2001).

\section{mRNA Microarray analysis}

Total RNA was isolated from intestine segments located $\sim 1.5 \mathrm{~cm}$ anterior to the cecum from E14.5 Klf5 ${ }^{\Delta / \Delta}$ and $K l f 5^{w t / W t} S h h^{E G F P / C r e+}$ embryos (n=3 samples/genotype, each sample a pool of two intestines) using the Qiagen MicroRNA Kit. The RNA quality and quantity assessment, cDNA probe preparation, hybridization to the Affymetrix Mouse Gene 1.0 ST Array, and image scan were carried out in the CCHMC Affymetrix Core using standard procedures. The hybridization data were statistically analyzed as described in detail in the supplementary methods. The complete dataset can be accessed from geo@ ncbi.nlm.nih.gov by the accession number GSE39624. The hybridization data were sequentially subjected to normalization, transformation, filtration, functional classification and pathway analysis as previously described (Xu et al., 2009). Data analysis was performed with Genespring GX11. All probe sets on the array were pre-filtered based on their signal intensity such that a probe was used for further analysis if the probe signal intensity was $>35$ th percentile in at least 2 of 3 samples. Differentially expressed genes in response to KIf 5 deletion vs. control mice were identified using an unpaired Student t-test. Changes in gene expression were considered statistically significant if their $\mathrm{P}$ value was $<0.05$ and fold-change was $>1.5$. Gene Ontology Analysis was performed using the publicly available web-based tool DAVID (database for annotation, visualization, and integrated discovery) (Huang da et al., 2009). A gene ontology term was considered to be overly represented when a Fisher's exact test $\mathrm{P}$ value is $\leq 0.001$ and gene hits are $\geq 5$. Potential protein/protein or protein/DNA interactions were identified using Ingenuity Pathway Analysis (IPA, Ingenuity). IPA software maps the differentially expressed genes identified from the microarray experiment onto the interactome according to Ingenuity Pathway Knowledge Base, a curated database of published literature findings on mammalian biology. Genetic networks preferentially enriched for input genes were generated based on their connectivity. Likely upstream transcriptional regulators were predicted based on the significant overlaps between differentially expressed genes in $K l f 5^{\Delta / \Delta}$ mice and known targets of each transcription factor in the Ingenuity knowledge base. Statistical scores were calculated to rank the resulting networks and pathways using Fisher's right tailed exact test. The score indicates 
the degree of relevance of a network to the input gene set, which takes into account the number of network-eligible genes and the size of the network.

\section{Electron Microscopy}

The distal small intestine from three E18.5 Klf5 $5^{\Delta / \Delta}$ and $K l f 5^{w t / w t} S h h^{E G F P / c r e t}$ fetuses was fixed in $3 \%$ gluteraldehyde/.175M sodium cacodylate buffer followed by 1 hour in $1 \%$ osmium tetroxideprior to embedding in LX112. Sections were analyzed using a Hitachi 7600 transmission electron microscope fitted with an AMT Advantage Plus $2 \mathrm{~K} \times 2 \mathrm{~K}$ digital camera.

\section{Cellular proliferation}

To quantify cellular proliferation, E16.5 embryos were sagittally sectioned until the midline of the embryo was reached as determined by the presence of the bladder, a midline organ. The percentage of proliferating cells was determined by counting the number of phosphohistone $\mathrm{H} 3$ positive intestinal epithelial nuclei and the total number of intestinal epithelial nuclei within 3,20x fields per $6 \mu \mathrm{m}$ section. Three sections were evaluated per embryo acquired approximately $60-80 \mu \mathrm{m}$ apart. Four control and four $K l f 5^{\Delta / \Delta}$ embryos were evaluated. Statistical significance was determined using a 2-tailed, Student T-test of unequal variance.

Pregnant dams were injected i.p. with $50 \mu \mathrm{g} / \mathrm{g}$ body weight 5 'bromo-deoxyuridine (Invitrogen) on E16.5. Embryos were collected 2 hours post injection and fixed in 4\% paraformaldehye/PBS for immunohistochemistry.

\section{Promoter construct generation and transient transfection assays}

Promoter constructs were generated in pGL3 basic (Promega) by subcloning regions of the mouse FOXA1 locus isolated by restriction enzyme digestion and/or PCR amplification of plasmid and phage DNA provided by Kenneth S. Zaret (U of Penn, IRM, Philadelphia, PA). mElf3 promoter constructs were kindly provided by Angie Rizzino (Hou et al., 2004). HEK293T cells were plated $\left(2.5 \times 10^{5}\right.$ cells/well). DNA was transfected into cells using FUGENE 6 (Roche) in the following ratios: luciferase promoter (500 ng), pcDNA 3.1 expression vector (450 ng), pRL-Tk-Renilla (50 ng). Triplicate wells were harvested 24 hours later and each experiment was performed at least 4 times. Luciferase activity was normalized to renilla activity per well and triplicate averages determined. The average luciferase activity of each construct was normalized by subtracting the average luciferase activity of the parent constructs.

\section{RESULTS}

\section{Deletion of KIf5 causes abnormal intestinal morphogenesis}

To understand the role of KLF5 in maturation of the fetal intestinal epithelium, KIf $f^{f l o x} / f l o x$ $S h h^{E G F P / C r e+/-}$ (henceforth, KIf5 ${ }^{\Delta / \Delta}$ ) mice were generated in which Cre expression is controlled by the endogenous Shh promoter (Harfe et al., 2004). Shh and Klf5 expression were detected by E10 in the endodermal epithelium (Kolterud et al., 2009; Moore-Scott et al., 2007). In control E14.5 embryos, KLF5 was present in nuclei of all cells comprising the pseudostratified intestinal epithelium (Fig. 1A). During villus morphogenesis, higher levels of KLF5 were evident in the intervillus regions (Fig. 1A'). In efficiently recombined $K I f 5^{\Delta / \Delta}$ embryos, KLF5 staining was absent throughout the distal small intestine and colonic epithelium as early as E14.5 (Fig. 1B). In more proximal regions of the intestine and the distal stomach, recombination of the Klf5 floxed allele was less efficient (Fig. 1B, Suppl. Fig. 1A-D) as evidenced by persistent expression of KLF5 in subsets of cells in these regions. KLF5 was generally undetectable in more distal regions of the intestine at E15.5. 
KLF5 was not detected within the epithelium of the fore stomach, consistent with previous findings that higher levels of $S h$ are expressed in the forestomach than in the hindstomach (Bitgood and McMahon, 1995; Kolterud et al., 2009).

$K I f 5^{\Lambda / \Delta}$ pups were present at a normal Mendelian ratio at E18.5 but died immediately after birth of respiratory distress likely due to expression of $S h h^{E G F P / C r e}$ and deletion of Klf5 in the lung epithelium, an observation consistent with previous studies in which KIf5 was deleted from the embryonic respiratory epithelium (Wan et al., 2008). Dissection of the gastrointestinal tracts of E14.5, E16.5 and E18.5 fetuses revealed that proximal-distal patterning occurred normally, since a cecum was present in all Klf5 $5^{\Delta / \Delta}$ embryos (Fig. 1CD). The small intestine and crown-to-rump lengths were assessed and a reduction in intestinal length was observed at E18.5, Klf5 $5^{\mathrm{wt} / \mathrm{wt}} / \mathrm{Sh} h^{E G F P / C r e+}(3.04 \mathrm{~cm} \pm .158$ s.e.m.) and $K I f 5^{\Delta / \Delta}(2.3 \mathrm{~cm} \pm .154$ s.e.m.) fetuses ( $\mathrm{n}=5$, two tailed Student $\mathrm{t}$-Test, $\mathrm{P}<.02)$. At E18.5, the $K l f 5^{\Delta / \Delta}$ fetal intestines were relatively transparent and slightly dilated compared to controls (Fig. 1C-D). There was no evidence of obstruction within the intestinal lumen. Serial sectioning revealed that the anal-rectal junction formed normally (data not shown).

Histological examination of E18.5 Klf5 ${ }^{\Delta / \Delta}$ fetuses revealed a severe disruption in intestinal maturation (Fig. 2). By E18.5, the crypt-villus axis was established throughout control fetal intestines and terminal differentiation of enterocytes, goblet cells, and enteroendocrine cells was evident (Fig. 2A, C, E, G). The translucent appearance of E18.5 Klf $5^{\Delta / \Delta}$ intestines was likely attributable to impaired villus morphogenesis. In proximal regions of the $K I f 5^{\Delta / \Delta}$ small intestine, where Klf5 was not as efficiently deleted between E14-E16, short villus like structures were frequently present. Although the Klf5-deficient and control small intestines were both lined by columnar epithelial cells (Fig. $2 \mathrm{G}$ vs. H), the distal $K I f 5^{\Delta / \Delta}$ intestinal epithelium did not contain distinct villus structures, and epithelial differentiation was dramatically impaired (Fig. 2B, D, F). KIf $5^{\text {flox/flox }} S h h^{C r e E R T 2}$ fetuses exposed to tamoxifen on E13.5 exhibited a similar phenotype (Fig. S2) demonstrating that the phenotypes observed in $K I f 5^{\Delta / \Delta}$ intestinal epithelium were due to loss of KLF5 at the time of villus formation. The reduction in differentiated goblet cells was visualized by staining with Alcian blue and for the calcium activated chloride channel (CLCA3). The few goblet cells detected in KLF5-deficient epithelium were usually associated with rare, rudimentary villuslike structures (Fig. 2A-B (arrows), S2D). Goblet cells were also sparse in the colon that was lined by a flattened epithelium (Fig. 2A vs. B, arrowheads; 5G vs. H). Fewer cells stained for the neuroendocrine marker chromogranin A in $K I f 5^{\Delta / \Delta}$ fetuses (Fig. $2 \mathrm{C}$ vs. D). In contrast to the well-organized brush border present in normal enterocytes, the intestinal epithelial cells of $K l f 5^{\Delta / \Delta}$ fetuses had abnormally shaped, disorganized microvilli at the luminal surface (Fig. 2E vs. F arrowheads). Tight junctions between cells at the apical surface appeared normal in $K l f 5^{\Delta / \Delta}$ tissue (Fig. 2 E-F arrows).

\section{Intestinal epithelial cell proliferation in the absence of KLF5}

The association of KLF5 with cellular proliferation in the adult intestine prompted an evaluation of proliferation in the embryonic intestinal epithelium of $K l f 5^{\Delta / \Delta}$ embryos (Dong and Chen, 2009). Staining for phospho-histone H3, BrdU, and Ki67 identified proliferating cells within the intestinal epithelium of both control and Klf5-deficient embryos.

Proliferation was observed throughout the intestinal epithelium and mesenchyme of $K l f 5^{\Delta / \Delta}$ and control embryos at E14.5 (Fig. 3A-B). At E16.5 and E18.5, proliferating epithelial cells were restricted to the intervillus regions in controls (Fig. 3C, G, arrowheads). In contrast, proliferating $K I f 5^{\Delta / \Delta}$ epithelial cells were observed in the flattened regions and on the rare villus-like projections (Fig. 3D, H, arrows). The number of intestinal epithelial cells proliferating at E16.5 was quantified in control and $K l f 5^{\Delta / \Delta}$ fetuses. A significant increase in the percentage of phospho-histone $\mathrm{H} 3$ positive nuclei was observed within the intestinal epithelium of $K l f 5^{\Delta / \Delta}$ fetuses (33.42 \pm sem 2.3) vs. (22.09 \pm sem 2.02, $\left.P \leq 0013\right)$ in controls. 
Changes in intestinal epithelial cell death were not detected in $K I f 5^{\Delta / \Delta}$ fetuses by TUNEL analysis performed on adjacent E16.5 sections. Positive TUNEL staining was detected within the livers of both control and $K l f 5^{\Delta / \Delta}$ fetuses (data not shown).

Cyclin D1 mediates progression of the G1/S phase transition of the cell cycle and is also involved in the commitment to differentiate in some cells (for review see, Caldon et al., 2010). In other cell types, Cyclin D1 is a direct target of KLF5 (Bateman et al., 2004; Liu et al., 2010). Immunohistochemical staining for cyclin D1 was detected within the intervillus regions of the control intestinal epithelium but was absent from the $K l f 5^{\Delta / \Delta}$ epithelium (Fig. $3 \mathrm{E}$ vs. F) at E16.5. These observations indicate that within the developing intestinal epithelium, cyclin D1 expression is also likely dependent on the presence of KLF5.

\section{Failure of villus morphogenesis in $K I f 5^{\Delta / \Delta}$ intestines}

Reminiscent of the $K I f 5^{\Delta / \Delta}$ intestine, a translucent, fluid-filled intestine, lacking morphological villi and possessing an abnormal brush border was observed following ectopic expression of SOX2 in the intestinal epithelium (Raghoebir et al., 2012). SOX2 is normally restricted to the anterior endodermal epithelium (e.g., esophagus and stomach), whereas CDX2 is restricted to the intestine. Intestinal endoderm lacking CDX2 possessed characteristics of foregut endoderm similar to esophagus (Gao et al., 2009). To assess proximal-distal patterning, we evaluated SOX2 and CDX2 expression in $K l f 5^{\Delta / \Delta}$ embryos. The pattern of SOX2 and CDX2 expression was not changed by deletion of KIf5 (Fig. 4AB, 5G-H) supporting the concept that early proximal-distal specification of the Klf5 $5^{\Delta / \Delta}$ intestinal epithelium occurred.

Temporally, villus morphogenesis progresses from proximal-distal regions between E1516.5 (Fig. 4C, E, G). At E14.5, KIf5, Sox9, FoxA1, Shh, Ihh, and Fzd5 are expressed uniformly throughout the epithelium. As villi form, the expression of Klf5, Sox 9, Shh, Ihh, and $F z d 5$ becomes restricted to the intervillus region (Kolterud et al., 2009; Madison et al., 2005; van Es et al., 2005) and FOXA1 expression becomes limited to a few scattered cells (Fig. 4G, I). At E14.5, FOXA1 and SOX9 were uniformly expressed throughout the epithelium of control and Klf5 ${ }^{\Delta / \Delta}$ embryos (data not shown). By E15.5, SOX9 expression in controls was decreased in the tips of newly formed villi in proximal regions of the intestine, but maintained throughout the epithelium in more distal locations (Fig. 4C). Although some folding of the $K l f 5^{\Delta / \Delta}$ epithelium was detected proximally at E15.5, distinct villi were rarely observed and SOX9 was uniformly expressed in both the proximal and distal intestine (Fig. 4D). By E16.5, villi were formed throughout the small intestines of control embryos with a concomitant reduction in the number of cells expressing FOXA1 (Fig. 4G). In contrast, villi were usually absent from distal regions of the small intestine and FOXA1 and SOX9 staining was maintained at high levels throughout the intestinal epithelium of E16.5 KIf $5^{\Delta / \Delta}$ fetuses (Fig. 4H, data not shown). At E18.5, Klf5 $5^{\Delta / \Delta}$ epithelium expressed high levels of SOX9 and FOXA1 except where rare, villus-like structures formed (Fig. 4F, J). These data indicate that Klf5 is required for initiation of villus morphogenesis within the distal intestine and suggest that the $K I f 5^{\Delta / \Delta}$ epithelial cells retain earlier embryonic characteristics.

\section{Maintenance of signaling pathways controlling villus morphogenesis}

Epithelial-mesenchymal crosstalk mediated by platelet-derived growth factor (PDGF) and Hedgehog signaling pathways is thought to regulate intestinal villus morphogenesis. PDGFA, SHH, and IHH are normally produced by the epithelium and signal to the underlying mesenchyme (Karlsson et al., 2000; Kolterud et al., 2009; Ramalho-Santos et al., 2000). PDGFA signals to PDGFRa in the mesenchyme, resulting in clusters of condensed mesenchymal cells that provide reciprocal signals (e.g., BMPs) back to the epithelium during villus formation (Karlsson et al., 2000). In other cell types, KLF5 regulates Pdgfa 
expression (Aizawa et al., 2004; Shindo et al., 2002). To determine whether alterations in PDGFA signaling were associated with the absence of villus formation in $K I f 5^{4 / \Delta}$ embryos, QRT-PCR was performed. At E14.5, Pdgfa mRNA levels were not altered by deletion of KIf5. At E16.5, Pdgfa mRNA levels were significantly increased in the distal small intestines of Klf5 $5^{\Delta / \Delta}$ intestines (Fig. 5I, data not shown). These data suggest that in the embryonic intestine KLF5 is not required for expression of Pdgfa. PDGFRa was detected in a thin layer of mesenchyme cells subjacent to the epithelium and in clustersin the proximal small intestines of control and $K l f 5^{\Delta / \Delta}$ tissue at E15.5 (Fig. 5A-B). In controls, mesenchymal clusters were associated with emerging villi. By E16.5, villi were present throughout the small intestines of control embryos and PDGFRa expression was concentrated within the villus tip mesenchyme. In contrast, villi were absent from distal regions of the $K l f 5^{\Delta / \Delta}$ small intestine. Some clusters of PDGFRa expressing cells were detected within the E16.5 Klf5 $5^{\Delta / \Delta}$ mesenchyme associated with a presumed initiated villus that failed to mature (Fig. 5D, arrows). Regions of flattened epithelium were also present that were not associated with PDGFRa positive mesenchymal clusters (Fig. 5D, arrowheads). The presence of PDGFRa indicates that the Klf $5^{\Delta / \Delta}$ mesenchyme is likely competent to respond to PDGFA.

The intestinal epithelium of $K I f 5^{\Delta / \Delta}$ fetuses expressed $S h h$ between E14.5-E16.5 as determined by QRT-PCR and in situ hybridization (Fig. 5I, data not shown). In contrast, Ihh mRNA was decreased in $K I f 5^{4 / \Delta}$ cDNA at both time points (Fig. 5I, data not shown). Known targets of HH signaling, including Ptch1, Gli1, Gli2, Bmp2, Bmp4, and Hhip, are expressed in the developing mesenchyme (Kolterud et al., 2009; Madison et al., 2005). In situ hybridization demonstrated that $B m p 2$ and $B m p 4$ were normally expressed by the $K l f 5^{\Delta / \Delta}$ mesenchyme at E15.5 (Fig. 5E-F, data not shown). At E16.5, Ptch1 and Gli2 mRNAs were significantly increased in the Klf5 ${ }^{\Delta / \Delta}$ intestine (Fig. 5I) suggesting that SHH is signaling to the mesenchyme. Since SHH signaling to the mesenchyme is required for intestinal smooth muscle development (McLin et al., 2009; Ramalho-Santos et al., 2000), E18.5 embryos were stained for aSMA. aSMA staining demonstrated the presence of two distinct smooth muscle layers in the control and $K l f 5^{\Delta / \Delta}$ mesenchyme (Fig. 5J-K). Like $K I f 5^{\Delta / \Delta}$ fetuses, dilation of the small intestine and reduced villus size were observed in $I h h$ $(-/-)$ progeny, a finding partially attributed to the absence of enteric neurons (RamalhoSantos et al., 2000). Staining for the enteric neuron progenitor marker SOX2 (Heanue and Pachnis, 2011) identified these cells within the mesenchyme of control and $K l f 5^{\Delta / \Delta}$ small intestine and colon at E14.5 and E18.5 (Fig. 5G-H, data not shown). Taken together, these data suggest that epithelial-mesenchymal signaling pathways previously shown to be important for villus formation are intact in $K l f 5^{\Delta / \Delta}$ intestines.

\section{Identification of KLF5 target genes}

To identify putative KLF5 target genes that mediate villus morphogenesis and epithelial maturation, we performed mRNA microarray analysis on E14.5 intestinal samples. We identified 511 mRNAs that decreased $\geq 1.5$ fold and 133 mRNAs that increased $\geq 1.5$ fold in the KIf $5^{\Delta / \Delta}$ intestine (Fig. 6A). Gene networks generated using Ingenuity Pathway Analysis of mRNAs down regulated in response to KIf5 deletion were functionally enriched in "transcriptional regulation of cell differentiation" and "cell adhesion" (Fig. 7A). Within the cell differentiation related sub-network, mRNAs encoding transcription factors known to regulate terminal differentiation and maturation in the intestine (for review see, Heath, 2010 and Spence et al., 2011) were coordinately decreased in response to Klf5 deletion including Atoh1 (-3.42), Ppary (-2.25), Cebpa (-2.37), Cdx1 (-1.88), Cdx2 (-1.53), Hnfla (-1.94), $\mathrm{Hnf4a}(-3.87)$ and $\mathrm{Hnf} 4 \gamma(-3.87)$. CDX2 positively regulates expression of $\mathrm{Hnf} 4 \mathrm{a}$ and Cdx1 (Boyd et al., 2010). CDX2 and HNFla synergistically regulate cis elements in the promoters of several intestine-specific genes (Mitchelmore et al., 2000). Other mRNAs 
encoding transcription factors known to mediate intestinal epithelial maturation were also decreased at E14.5 including Elf3 (-9.09), Ascl2 (-4.42), Neurog3 (-2.8), and IsX1 (- 1.79) (Spence et al., 2011). QRT-PCR analyses confirmed Atoh1, Cdx1, Ascl2, and Elf3 were expressed at significantly lower levels at E14.5 and E16.5, indicating that their decreased expression was not likely attributable to a developmental delay in the KIf $5^{\Delta / \Delta}$ fetuses (Fig. 6B). Similarly, HNF4a protein levels were reduced in the E15.5 intestine (Fig. S3A vs. B), confirming the near total reduction in expression of this factor. This observation is consistent with the role of HNF4a in promoting terminal differentiation of intestinal epithelial cells and the observed inhibition of terminal differentiation in the Klf $5^{\Delta / \Delta}$ epithelium (Garrison et al., 2006; Olsen et al., 2005). While unchanged at E14.5, FoxA1 mRNA was increased in $K I f 5^{\Delta / \Delta}$ intestines at E16.5 and E18.5 (Fig. 6B, data not shown), consistent with protein expression data (Fig. $4 \mathrm{H}, \mathrm{J}$ ). Together, these results demonstrate that loss of KLF5 disrupts the program of networked transcriptional regulators of intestinal epithelial differentiation.

In the "cell adhesion" related sub-network, mRNAs encoding claudins $2,3,7,8$, and 18 and tight junction protein 3 were decreased in $K I f 5^{\Delta / \Delta}$ intestines. Claudins are the structural and molecular building blocks of tight junctions involved in maintaining epithelial integrity, establishing micro-environments and contributing to the overall shape of tissues or cells (Gupta and Ryan, 2010).

In agreement with our protein and mRNA analyses of the SHH and PDGF signaling pathways, the mRNA microarray data only detected changes in $I h h(-1.95)$ mRNA and a modest increase in Hhip $(+1.55)$. Although Wnt signaling has not previously been associated with villus morphogenesis, it is critical for the maintenance of the adult crypt-villus axis and the control of stem cell renewal (Spence et al., 2011). Four components of the WNT signaling pathway expressed in the adult intestinal crypt were altered in $K l f 5^{\Delta / \Delta}$ intestines: Fzd5 (-1.79), Lgr5 (-3.38), Lgr4 (-1.6), and Dkk2 (+1.5) (Heath, 2010; van Es et al., 2005). QRT-PCR confirmed the reduction in Fzd5 mRNA levels in E14.5 and E16.5 Klf5 $5^{\Delta / \Delta}$ intestines. Although a reduction in $L g r 5$ mRNA levels was detected in E14.5 Klf5 $5^{\Delta / \Delta}$ intestines, Lgr5 expression was increased at E16.5 and E18.5 (Fig. 6C, data not shown). Lgr 5 expression is regulated by canonical Wnt signaling (Heath, 2010). However, nuclear $\beta$ catenin staining was not observed in $K I f 5^{\Delta / \Delta}$ intestines (Fig. S3E vs. F), indicating that the canonical Wnt signaling pathway was not aberrantly activated in the absence of KLF5.

Intestinal maturation is associated with formation of a highly organized luminal brush border. Consistent with the abnormal microvilli observed in E18.5 Klf5 $5^{\Delta / \Delta}$ intestines (Fig. 2F), mRNAs associated with establishment and maintenance of microvilli and cell polarity were decreased at E14.5, including Vil1, annexins A4, A11, A13; keratins 8, 19; myosins 15b, 1a, 1d, 5b, 5c, and 7b, brush border kinase Prkg2, LIgl2, Rab25, Eps8-like genes and others (Hein et al., 2011; Jarchau et al., 1994; Offenhauser et al., 2004; Sripathy et al., 2011; Tocchetti et al., 2010). QRT-PCR confirmed the reduction and persistent decrease in Vill, LIg12, Eps812 and Eps813 mRNA levels at E14.5 and E16.5 (Fig. 6C, data not shown). IHC confirmed reduced KRT8 expression (Fig. S3C vs. D).

We compared published mRNA microarray data from E14.5 Klf5 $5^{\Delta / \Delta}$ bladders (Bell et al., 2011) with the present data, identifying 112 mRNAs similarly influenced by Klf5 deletion in both tissues, including Elf3, Grhl3, Ppary, Ovol1, Rar $\beta$, keratins 7, 8, and 19, Rab25, Sfn, and Llgl2 (Suppl. Table 1). As assessed by QRT-PCR, Elf3, Grhl3, Ppary, Ovol1, and Llgl2 mRNAs were decreased in E14.5 Klf5 $5^{\Delta / \Delta}$ intestines (Fig. 6B, C). Elf3, Grhl3, Ovol1, and $S f n$ have been implicated in promoting terminal differentiation in epithelial cells in multiple tissues suggesting that KLF5 functions upstream of a common set of target genes that influences their terminal differentiation (Bell et al., 2011; Ng et al., 2002; Teng et al., 2007; 
Xin et al., 2010; Yu et al., 2008; Yu et al., 2009). Further comparison of these 112 mRNAs with KLF5 binding sites identified by Parisi et al. (2010) using ChIP-Seq in ES cells revealed 24 genes commonly regulated in intestine, bladder and ES cells (Suppl. Table 1)

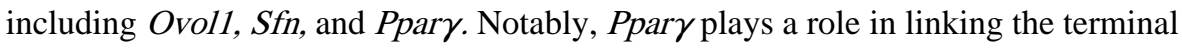
differentiation and cell-adhesion sub-networks (Fig. 7A).

\section{KLF5 regulates Elf3 by inhibiting FoxAl expression}

In the intestines of $K I f 5^{\Delta / \Delta}$ embryos, Fox $A 1$ mRNA levels were increased and Elf3 mRNA levels decreased at all developmental time points evaluated. Elf3 mutant embryos share several phenotypic characteristics with $K I f 5^{\Delta / \Delta}$ intestines, including abnormalities in villus formation and epithelial differentiation (Ng et al., 2002). Mutation of FoXA1 and FoXA2 also caused abnormal intestinal epithelial differentiation (Ye and Kaestner, 2009). Therefore, we assessed potential regulatory interactions between these genes. The continued expression of FoxA1 after deletion of Klf5 suggested that KLF5 might repress FoxA1 transcription. Consistent with this, increased expression of KLF5 inhibited mFoxA1 promoter activity in HEK293T cells (Fig. 7B). FOXA1 promoter deletion analysis indicated that sequences immediately surrounding the FoxA1 start site (NM_008259), +43 to +355 were sufficient to confer inhibition by KLF5. Notably, +162 to +318 is a "GC-rich" region containing two putative KLF5 binding sites containing the sequence CACCC. We next evaluated the ability of KLF5 to regulate Elf3 promoter constructs (Hou et al., 2004). Neither activation of the Elf3 promoter by over expression of KLF5 in HEK293T cells, nor inhibition of Elf3 promoter activity in the presence of KIf5 SiRNA in DLD-1 cells was observed (Fig. 7C, data not shown). These data demonstrate that KLF5 does not regulate this proximal promoter region of Elf3. In contrast, we found that FOXA1 significantly repressed the activity of Elf3-luciferase reporter constructs in HEK293T cells (Fig. 7C). Together, these results suggest that KLF5 restricts FoX 11 expression during intestinal development, in turn allowing expression of Elf3 that promotes villus formation and epithelial differentiation.

\section{DISCUSSION}

Deletion of Klf5 in the early endoderm using the Shh-Cre transgene demonstrated that KLF5 is required for villus morphogenesis and differentiation of multiple intestinal epithelial cell types. Temporally controlled deletion of Klf5 by tamoxifen administration at E13.5 indicated that KLF5 is required between E13.5-E14.5, just prior to villus emergence.

The $K l f 5^{\Delta / \Delta}$ intestines failed to form villi despite expressing factors known to mediate epithelial-mesenchymal signaling essential for villus formation including Shh, Bmp4, PDGFA, and PDGFRa. The mesenchyme of $K I f 5^{\Delta / \Delta}$ intestines was competent to respond to epithelial HH signals as evidenced by increased Ptc1 and Gli2 expression at E16.5 likely mediated by continued expression of Shh by the epithelium. Although deletion of Klf5 was associated with perturbed regulation of several components of the HH pathway, it is not clear how these alterations contributed to the observed absence of villi. Inhibition of all $\mathrm{HH}$ signaling by epithelial over-expression of the HH inhibitor, Hhip, resulted in formation of a proliferative, flattened epithelium similar to that generated by KIf5 deficiency (Madison et al., 2005). A less severe intestinal phenotype was seen following deletion of Shh or Ihh individually (Ramalho-Santos et al., 2000). The reduction in Ihh expression alone is not sufficient to explain the lack of villus formation in $K l f 5^{\Delta / \Delta}$ intestines, since $I h h(-/-)$ fetuses are unable to maintain proliferation in the intervillus region resulting in small villi (Ramalho-Santos et al., 2000). Proliferating cells were detected throughout the Klf5 ${ }^{\Delta / \Delta}$ intestinal epithelium at all developmental time points in the absence of formation of an intervillus region. 
Villus emergence is associated with the formation of condensed clusters of mesenchyme expressing Pdgfra, Bmp4, and Bmp2 (Karlsson et al., 2000). In the present study, subepithelial clusters were present in the $K I f 5^{\Delta / \Delta}$ mesenchyme particularly in the proximal intestine. These clusters were associated with emerging villi that subsequently failed to elongate and mature resulting in a few very short, villus-like structures. Within distal segments of the $K l f 5^{\Delta / \Delta}$ intestine, where KLF5 recombination occurs efficiently at an earlier developmental time point, mesenchymal clusters expressing PDGFRa were not observed as frequently and a flattened epithelium was observed at later developmental timepoints. Since E-cadherin was detected not only on the lateral membranes of the intestinal epithelium but also the luminal and basal surfaces (Fig. $2 \mathrm{G} \mathrm{vs.} \mathrm{H),} \mathrm{the}$ inefficiency in inducing mesenchymal cluster formation could be attributable to a failure of PDGFA to be normally partitioned to the basal surface of the epithelial cells. Consistent with this possibility, the microarray analysis of intestines from $K I f 5^{\Delta / \Delta}$ embryos identified reduced expression of mRNAs involved in cellular trafficking, including several members of the $R a b$ family.

The present data indicate that specification of the crypt-villus axis is required for terminal differentiation of the intestinal epithelium. In the absence of villi, $K l f 5^{\Delta / \Delta}$ E18.5 fetuses lacked an apical brush border; goblet and enteroendocrine cells were rarely detected; and reductions in the expression of mRNAs associated with maturation of specific cell lineages, including Elf3 (enterocytes), Atoh1, Tff3 (goblet cells), and Neurog3 (enteroendocrine cells) were demonstrated. Supportive of this concept, newborn Klf5 ${ }^{f l / f l}$; VillinCre mice also had sparse villi and most died soon after birth (McConnell et al., 2011). Terminally differentiated intestinal epithelial cells are absent in mice lacking $C d \times 2$ (Gao et al., 2009; Hryniuk et al., 2012). Analogous to the KIf5 ${ }^{\Delta / \Delta}$ intestines, Hnfla, Hnf-4a, IsX and $C d x 1$ mRNAs were reduced in E12.5-E14.5 Cdx2 null embryos in which villus hypoplasia was observed by E16.5 in the presence of a highly proliferative epithelium (Gao et al., 2009). In contrast, nascent villi formed in Tcf4 (-/-) embryos as well as terminally differentiated enterocytes and goblet cells (Korinek et al., 1998). Taken together, these observations support the concepts that villus morphogenesis is closely linked with terminal maturation of intestinal epithelial cells and that $K I f 5$ and $C d x 2$ are required for intestinal morphogenesis and terminal differentiation.

The CDX-HNF centered "transcriptional regulation of cell differentiation" and the claudin centered "cell adhesion" sub-networks identified by Ingenuity Pathway Analysis are interconnected since CDX and HNF family members can transcriptionally activate the Claudins. The present study supports the concept that CDX and HNF factors work in concert with Claudins to control epithelial cell shape changes likely required for villus morphogenesis. Villus morphogenesis is similarly impaired in $K l f 5^{\Delta / \Delta}$ and $C d \times 2(-/-)$ embryos (Gao et al., 2009). Supportive of this concept, late fetal loss of intestinal epithelial E-cadherin resulted in regions lacking villi and other regions possessed blunted or misshapened villi (Bondow et al., 2012).

Upstream regulator analysis predicted FOXA1/2 as one of the most likely upstream regulators of intestinal epithelial maturation based on the significant overlap between down regulated genes in $K I f 5^{\Lambda / \Delta}$ mice and known transcriptional targets of FOXA1/2. Transcriptional network analysis supports the concept that FOXA1 is an important transcriptional hub regulating $\mathrm{Cdx}$ 2, $\mathrm{Hnfla}, \mathrm{Hnf4a}$ and $\mathrm{Hnf4} \gamma$ (Fig. 7A). The findings that FOXA1 expression is normally restricted during villus emergence, and that FOXA1 was maintained at high levels in KIf5 $5^{\Delta / \Delta}$ intestines, support the importance of our finding that KLF5 repressed the FoXA1 promoter in vitro. ChIP-seq data acquired from KLF5 overexpressing ES cells confirmed an interaction between KLF5 and the FoxA1 promoter supporting a model in which KLF5 directly regulates transcription of FoXA1 (Parisi et al., 
2010). The $K I f 5^{\Delta / \Delta}$ epithelium was highly proliferative and continued to express high levels of FOXA1 and SOX9 at developmental stages when the expression of both genes is normally restricted suggesting that the $K I f 5^{\Delta / \Delta}$ epithelium is maintained in an immature state. An undifferentiated epithelium that lacked villi also formed in mice after temporal deletion of KLF5 at E13.5, indicating that KLF5 activity is required at the onset of villus morphogenesis at $\sim$ E14.5-E15.5, co-incident with the temporal decrease in FOXA1 expression. Since KLF5 and FOXA1 are co-expressed throughout earlier phases of gut morphogenesis, the temporal signal that would induce KLF5 to inhibit FOXA1 expression is currently unknown. KLF5 both activates and inhibits gene expression depending on the post-translational modifications made in response to extracellular stimuli (Bateman et al., 2004; Zheng et al., 2011). The failure of the KIf5 $5^{\Delta / \Delta}$ intestinal epithelium to mature is consistent with a recent report indicating that changes in the levels of FOXA1 can mediate dramatic changes in the activity of pre- established enhancers by altering the binding affinities of nuclear hormone receptors (Wang et al., 2011). FOXA1 recruits transcriptional inhibitors including HDAC7 and Groucho related genes to repress target gene expression (Malik et al., 2010; Santisteban et al., 2010). The finding that FOXA1 inhibited the Elf3 promoter, a gene required for maturation of the absorptive enterocytes within the intestine, provides a plausible mechanism by which KLF5 regulates intestinal development by controlling a network of transcription factors. In the context of enterocyte differentiation, KLF5 inhibits FoxA1 and thus allows expression of Elf3 to direct terminal differentiation of intestinal epithelial cells. Notably, KLF5 also interacts with class 1 HDACs (Zheng et al., 2011). In the fetal intestine, HDACs 1 and 2 are expressed by the epithelium and their expression declines between E13-E15, coincident with the onset of terminal differentiation and villus morphogenesis (Tou et al., 2004). Thus in the KLF5 deficient epithelium the promoters of some terminal differentiation markers may not be properly poised for activation, thus prohibiting intestinal maturation.

KLF5 is not required for embryonic intestinal epithelial cell proliferation. In the present study and after targeted deletion of KIf5 in the adult intestinal epithelium (McConnell et al., 2011), proliferation was maintained. An increase in the number of Ki67-positive mitotic cells was also observed postnatally in Klf5-deficient ocular surface epithelial cells, accompanied by failure to form goblet cells (Kenchegowda et al., 2011). Thus, in embryonic, postnatal, and adult epithelium, KLF5 is required for transitioning undifferentiated cells towards a terminally differentiated fate (Kenchegowda et al., 2011; McConnell et al., 2011).

In summary, these studies indicate a novel requirement of KLF5 to initiate morphogenesis of the early endoderm into a compartmentalized intestinal epithelium comprised of villi. The data support the concept that KLF5 orchestrates villus morphogenesis in part by repression of FoxA1 expression that in turn alleviates FOXA1 mediated repression of the terminal differentiation factor Elf3.

\section{Supplementary Material}

Refer to Web version on PubMed Central for supplementary material.

\section{Acknowledgments}

This work was funded in part by NIH grants R01:DK-092306 (S.M.B. and N.S.) and R01:HL-110964 (J.A.W.).

\section{References}

Aizawa K, Suzuki T, Kada N, Ishihara A, Kawai-Kowase K, Matsumura T, Sasaki K, Munemasa Y, Manabe I, Kurabayashi M, Collins T, Nagai R. Regulation of platelet-derived growth factor-A chain 
by Kruppel-like factor 5: new pathway of cooperative activation with nuclear factor-kappaB. J Biol Chem. 2004; 279:70-76. [PubMed: 14573617]

Bagheri-Fam S, Barrionuevo F, Dohrmann U, Gunther T, Schule R, Kemler R, Mallo M, Kanzler B, Scherer G. Long-range upstream and downstream enhancers control distinct subsets of the complex spatiotemporal Sox9 expression pattern. Dev Biol. 2006; 291:382-397. [PubMed: 16458883]

Bateman NW, Tan D, Pestell RG, Black JD, Black AR. Intestinal tumor progression is associated with altered function of KLF5. J Biol Chem. 2004; 279:12093-12101. [PubMed: 14726538]

Bell SM, Zhang L, Mendell A, Xu Y, Haitchi HM, Lessard JL, Whitsett JA. Kruppel-like factor 5 is required for formation and differentiation of the bladder urothelium. Dev Biol. 2011; 358:79-90. [PubMed: 21803035]

Besnard V, Wert SE, Hull WM, Whitsett JA. Immunohistochemical localization of Foxa1 and Foxa2 in mouse embryos and adult tissues. Gene Expr Patterns. 2004; 5:193-208. [PubMed: 15567715]

Bitgood MJ, McMahon AP. Hedgehog and Bmp genes are coexpressed at many diverse sites of cellcell interaction in the mouse embryo. Dev Biol. 1995; 172:126-138. [PubMed: 7589793]

Bondow BJ, Faber ML, Wojta KJ, Walker EM, Battle MA. E-cadherin is required for intestinal morphogenesis in the mouse. Dev Biol. 2012; 37:1-12. [PubMed: 22766025]

Boyd M, Hansen M, Jensen TG, Perearnau A, Olsen AK, Bram LL, Bak M, Tommerup N, Olsen J, Troelsen JT. Genome-wide analysis of CDX2 binding in intestinal epithelial cells (Caco-2). J Biol Chem. 2010; 285:25115-25125. [PubMed: 20551321]

Caldon CE, Sutherland RL, Musgrove E. Cell cycle proteins in epithelial cell differentiation: implications for breast cancer. Cell Cycle. 2010; 9:1918-1928. [PubMed: 20473028]

Dong JT, Chen C. Essential role of KLF5 transcription factor in cell proliferation and differentiation and its implications for human diseases. Cell Mol Life Sci. 2009; 66:2691-2706. [PubMed: 19448973]

Gao N, White P, Kaestner KH. Establishment of intestinal identity and epithelial-mesenchymal signaling by Cdx2. Dev Cell. 2009; 16:588-599. [PubMed: 19386267]

Garrison WD, Battle MA, Yang C, Kaestner KH, Sladek FM, Duncan SA. Hepatocyte nuclear factor 4alpha is essential for embryonic development of the mouse colon. Gastroenterology. 2006; 130:1207-1220. [PubMed: 16618389]

Gupta IR, Ryan AK. Claudins: unlocking the code to tight junction function during embryogenesis and in disease. Clin Genet. 2010; 77:314-325. [PubMed: 20447145]

Harfe BD, Scherz PJ, Nissim S, Tian H, McMahon AP, Tabin CJ. Evidence for an expansion-based temporal Shh gradient in specifying vertebrate digit identities. Cell. 2004; 118:517-528. [PubMed: 15315763]

Heanue TA, Pachnis V. Prospective identification and isolation of enteric nervous system progenitors using Sox2. Stem Cells. 2011; 29:128-140. [PubMed: 21280162]

Heath JK. Transcriptional networks and signaling pathways that govern vertebrate intestinal development. Curr Top Dev Biol. 2010; 90:159-192. [PubMed: 20691849]

Hein Z, Schmidt S, Zimmer KP, Naim HY. The dual role of annexin II in targeting of brush border proteins and in intestinal cell polarity. Differentiation. 2011; 81:243-252. [PubMed: 21330046]

Hou J, Wilder PJ, Bernadt CT, Boer B, Neve RM, Rizzino A. Transcriptional regulation of the murine Elf3 gene in embryonal carcinoma cells and their differentiated counterparts: requirement for a novel upstream regulatory region. Gene. 2004; 340:123-131. [PubMed: 15556300]

Hryniuk A, Grainger S, Savory JG, Lohnes D. Cdx function is required for maintenance of intestinal identity in the adult. Dev Biol. 2012; 363:426-437. [PubMed: 22285812]

Huang da W, Sherman BT, Lempicki RA. Systematic and integrative analysis of large gene lists using DAVID bioinformatics resources. Nat Protoc. 2009; 4:44-57. [PubMed: 19131956]

Jarchau T, Hausler C, Markert T, Pohler D, Vanderkerckhove J, De Jonge HR, Lohmann SM, Walter U. Cloning, expression, and in situ localization of rat intestinal cGMP-dependent protein kinase II. Proc Natl Acad Sci U S A. 1994; 91:9426-9430. [PubMed: 7937783]

Karlsson L, Lindahl P, Heath JK, Betsholtz C. Abnormal gastrointestinal development in PDGF-A and PDGFR- $a$ deficient mice implicates a novel mesenchymal structure with putative instructive properties in villus morphogenesis. Development. 2000; 127:3457-3466. [PubMed: 10903171] 
Kenchegowda D, Swamynathan S, Gupta D, Wan H, Whitsett J, Swamynathan SK. Conditional disruption of mouse Klf5 results in defective eyelids with malformed meibomian glands, abnormal cornea and loss of conjunctival goblet cells. Dev Biol. 2011; 356:5-18. [PubMed: 21600198]

Kolterud A, Grosse AS, Zacharias WJ, Walton KD, Kretovich KE, Madison BB, Waghray M, Ferris JE, Hu C, Merchant JL, Dlugosz AA, Kottmann AH, Gumucio DL. Paracrine Hedgehog signaling in stomach and intestine: new roles for hedgehog in gastrointestinal patterning. Gastroenterology. 2009; 137:618-628. [PubMed: 19445942]

Korinek V, Barker N, Moerer P, van Donselaar E, Huls G, Peters PJ, Clevers H. Depletion of epithelial stem-cell compartments in the small intestine of mice lacking Tcf-4. Nat Genet. 1998; 19:379383. [PubMed: 9697701]

Liu Y, Wen JK, Dong LH, Zheng B, Han M. Kruppel-like factor (KLF) 5 mediates cyclin D1 expression and cell proliferation via interaction with c-Jun in Ang II- induced VSMCs. Acta pharmacologica Sinica. 2010; 31:10-18. [PubMed: 20037604]

Livak KJ, Schmittgen TD. Analysis of relative gene expression data using real-time quantitative PCR and the 2(-Delta Delta C(T)) Method. Methods. 2001; 25:402-408. [PubMed: 11846609]

Madison BB, Braunstein K, Kuizon E, Portman K, Qiao XT, Gumucio DL. Epithelial hedgehog signals pattern the intestinal crypt-villus axis. Development. 2005; 132:279-289. [PubMed: 15590741]

Malik S, Jiang S, Garee JP, Verdin E, Lee AV, O’Malley BW, Zhang M, Belaguli NS, Oesterreich S. Histone deacetylase 7 and FoxA1 in estrogen-mediated repression of RPRM. Mol Cell Biol. 2010; 30:399-412. [PubMed: 19917725]

McConnell BB, Kim SS, Yu K, Ghaleb AM, Takeda N, Manabe I, Nusrat A, Nagai R, Yang VW. Kruppel-like factor 5 is important for maintenance of crypt architecture and barrier function in mouse intestine. Gastroenterology. 2011; 141:1302-1313. e1301-1306. [PubMed: 21763241]

McLin VA, Henning SJ, Jamrich M. The role of the visceral mesoderm in the development of the gastrointestinal tract. Gastroenterology. 2009; 136:2074-2091. [PubMed: 19303014]

Mitchelmore C, Troelsen JT, Spodsberg N, Sjostrom H, Noren O. Interaction between the homeodomain proteins $\mathrm{Cdx} 2$ and HNF1alpha mediates expression of the lactase-phlorizin hydrolase gene. Biochem J. 2000; 346(Pt 2):529-535. [PubMed: 10677375]

Moore-Scott BA, Opoka R, Lin SC, Kordich JJ, Wells JM. Identification of molecular markers that are expressed in discrete anterior-posterior domains of the endoderm from the gastrula stage to midgestation. Dev Dyn. 2007; 236:1997-2003. [PubMed: 17576135]

Nandan MO, Yang VW. The role of Kruppel-like factors in the reprogramming of somatic cells to induced pluripotent stem cells. Histol Histopathol. 2009; 24:1343-1355. [PubMed: 19688699]

Ng AY, Waring P, Ristevski S, Wang C, Wilson T, Pritchard M, Hertzog P, Kola I. Inactivation of the transcription factor Elf3 in mice results in dysmorphogenesis and altered differentiation of intestinal epithelium. Gastroenterology. 2002; 122:1455-1466. [PubMed: 11984530]

Offenhauser N, Borgonovo A, Disanza A, Romano P, Ponzanelli I, Iannolo G, Di Fiore PP, Scita G. The Eps8 family of proteins links growth factor stimulation to actin reorganization generating functional redundancy in the Ras/Rac pathway. Mol Biol Cell. 2004; 15:91-98. [PubMed: 14565974]

Oishi Y, Manabe I, Tobe K, Tsushima K, Shindo T, Fujiu K, Nishimura G, Maemura K, Yamauchi T, Kubota N, Suzuki R, Kitamura T, Akira S, Kadowaki T, Nagai R. Kruppel-like transcription factor KLF5 is a key regulator of adipocyte differentiation. Cell Metab. 2005; 1:27-39. [PubMed: 16054042]

Olsen L, Bressendorff S, Troelsen JT, Olsen J. Differentiation-dependent activation of the human intestinal alkaline phosphatase promoter by HNF-4 in intestinal cells. American journal of physiology Gastrointestinal and liver physiology. 2005; 289:G220-226. [PubMed: 15831710]

Parisi S, Cozzuto L, Tarantino C, Passaro F, Ciriello S, Aloia L, Antonini D, De Simone V, Pastore L, Russo T. Direct targets of Klf5 transcription factor contribute to the maintenance of mouse embryonic stem cell undifferentiated state. BMC Biol. 2010; 8:128. [PubMed: 20875108]

Raghoebir L, Bakker ER, Mills JC, Swagemakers S, Kempen MB, Munck AB, Driegen S, Meijer D, Grosveld F, Tibboel D, Smits R, Rottier RJ. SOX2 redirects the developmental fate of the 
intestinal epithelium towards a premature gastric phenotype. J Mol Cell Biol. 2012 Jul 6. (Epub ahead of print).

Ramalho-Santos M, Melton DA, McMahon AP. Hedgehog signals regulate multiple aspects of gastrointestinal development. Development. 2000; 127:2763-2772. [PubMed: 10821773]

Santisteban P, Recacha P, Metzger DE, Zaret KS. Dynamic expression of Groucho-related genes Grg1 and Grg3 in foregut endoderm and antagonism of differentiation. Dev Dyn. 2010; 239:980-986. [PubMed: 20108349]

Shindo T, Manabe I, Fukushima Y, Tobe K, Aizawa K, Miyamoto S, Kawai-Kowase K, Moriyama N, Imai Y, Kawakami H, Nishimatsu H, Ishikawa T, Suzuki T, Morita H, Maemura K, Sata M, Hirata Y, Komukai M, Kagechika H, Kadowaki T, Kurabayashi M, Nagai R. Kruppel-like zinc-finger transcription factor KLF5/BTEB2 is a target for angiotensin II signaling and an essential regulator of cardiovascular remodeling. Nat Med. 2002; 8:856-863. [PubMed: 12101409]

Spence J, Lauf R, Shroyer N. Vertebrate intestinal endoderm development. Dev Dyn. 2011; 240:501520. [PubMed: 21246663]

Sripathy S, Lee M, Vasioukhin V. Mammalian Llg12 is necessary for proper branching morphogenesis during placental development. Mol Cell Biol. 2011; 31:2920-2933. [PubMed: 21606200]

Sun X, Zhang L, Xie H, Wan H, Magella B, Whitsett JA, Dey SK. Kruppel-like factor 5 (KLF5) is critical for conferring uterine receptivity to implantation. Proc Natl Acad Sci U S A. 2012; 109:1145-1150. [PubMed: 22233806]

Teng A, Nair M, Wells J, Segre JA, Dai X. Strain-dependent perinatal lethality of Ovol1-deficient mice and identification of Ovol2 as a downstream target of Ovol1 in skin epidermis. Biochim Biophys Acta. 2007; 1772:89-95. [PubMed: 17049212]

Tocchetti A, Soppo CB, Zani F, Bianchi F, Gagliani MC, Pozzi B, Rozman J, Elvert R, Ehrhardt N, Rathkolb B, Moerth C, Horsch M, Fuchs H, Gailus-Durner V, Beckers J, Klingenspor M, Wolf E, Hrabe de Angelis M, Scanziani E, Tacchetti C, Scita G, Di Fiore PP, Offenhauser N. Loss of the actin remodeler Eps8 causes intestinal defects and improved metabolic status in mice. PLoS One. 2010; 5:e9468. [PubMed: 20209148]

Tou L, Liu Q, Shivdasani RA. Regulation of mammalian epithelial differentiation and intestine development by class I histone deacetylases. Mol Cell Biol. 2004; 24:3132-3139. [PubMed: 15060137]

van Es JH, Jay P, Gregorieff A, van Gijn ME, Jonkheer S, Hatzis P, Thiele A, van den Born M, Begthel H, Brabletz T, Taketo MM, Clevers H. Wnt signalling induces maturation of Paneth cells in intestinal crypts. Nat Cell Biol. 2005; 7:381-386. [PubMed: 15778706]

Wan H, Luo F, Wert SE, Zhang L, Xu Y, Ikegami M, Maeda Y, Bell SM, Whitsett JA. Kruppel-like factor 5 is required for perinatal lung morphogenesis and function. Development. 2008; 135:25632572. [PubMed: 18599506]

Wang D, Garcia-Bassets I, Benner C, Li W, Su X, Zhou Y, Qiu J, Liu W, Kaikkonen MU, Ohgi KA, Glass CK, Rosenfeld MG, Fu XD. Reprogramming transcription by distinct classes of enhancers functionally defined by eRNA. Nature. 2011; 474:390-394. [PubMed: 21572438]

Xin Y, Lu Q, Li Q. 14-3-3sigma controls corneal epithelial cell proliferation and differentiation through the Notch signaling pathway. Biochem Biophys Res Commun. 2010; 392:593-598. [PubMed: 20100467]

Xu Y, Saegusa C, Schehr A, Grant S, Whitsett JA, Ikegami M. C/EBP $\{$ alpha $\}$ is required for pulmonary cytoprotection during hyperoxia. Am J Physiol Lung Cell Mol Physiol. 2009; 297:L286-298. [PubMed: 19465518]

Ye DZ, Kaestner KH. Foxa1 and Foxa2 control the differentiation of goblet and enteroendocrine Land D-cells in mice. Gastroenterology. 2009; 137:2052-2062. [PubMed: 19737569]

Yu Z, Bhandari A, Mannik J, Pham T, Xu X, Andersen B. Grainyhead-like factor Get1/Grhl3 regulates formation of the epidermal leading edge during eyelid closure. Dev Biol. 2008; 319:56-67. [PubMed: 18485343]

Yu Z, Mannik J, Soto A, Lin KK, Andersen B. The epidermal differentiation-associated Grainyhead gene Get1/Grhl3 also regulates urothelial differentiation. EMBO J. 2009; 28:1890-1903. [PubMed: 19494835] 
Zheng B, Han M, Shu YN, Li YJ, Miao SB, Zhang XH, Shi HJ, Zhang T, Wen JK. HDAC2 phosphorylation-dependent Klf5 deacetylation and RARalpha acetylation induced by RAR agonist switch the transcription regulatory programs of p21 in VSMCs. Cell Res. 2011; 21:1487-1508.

[PubMed: 21383775] 


\section{Highlights}

The developing intestine requires KLF5 activity at the onset of villus morphogenesis.

Although proliferative, the Klf5-deficient intestinal epithelium fails to form villi.

Terminal differentiation of intestinal epithelium is impaired in the absence of KLF5.

KLF5 represses FoxAlgene expression.

Loss of Elf3 expression was associated with persistent expression of FoxAl. 


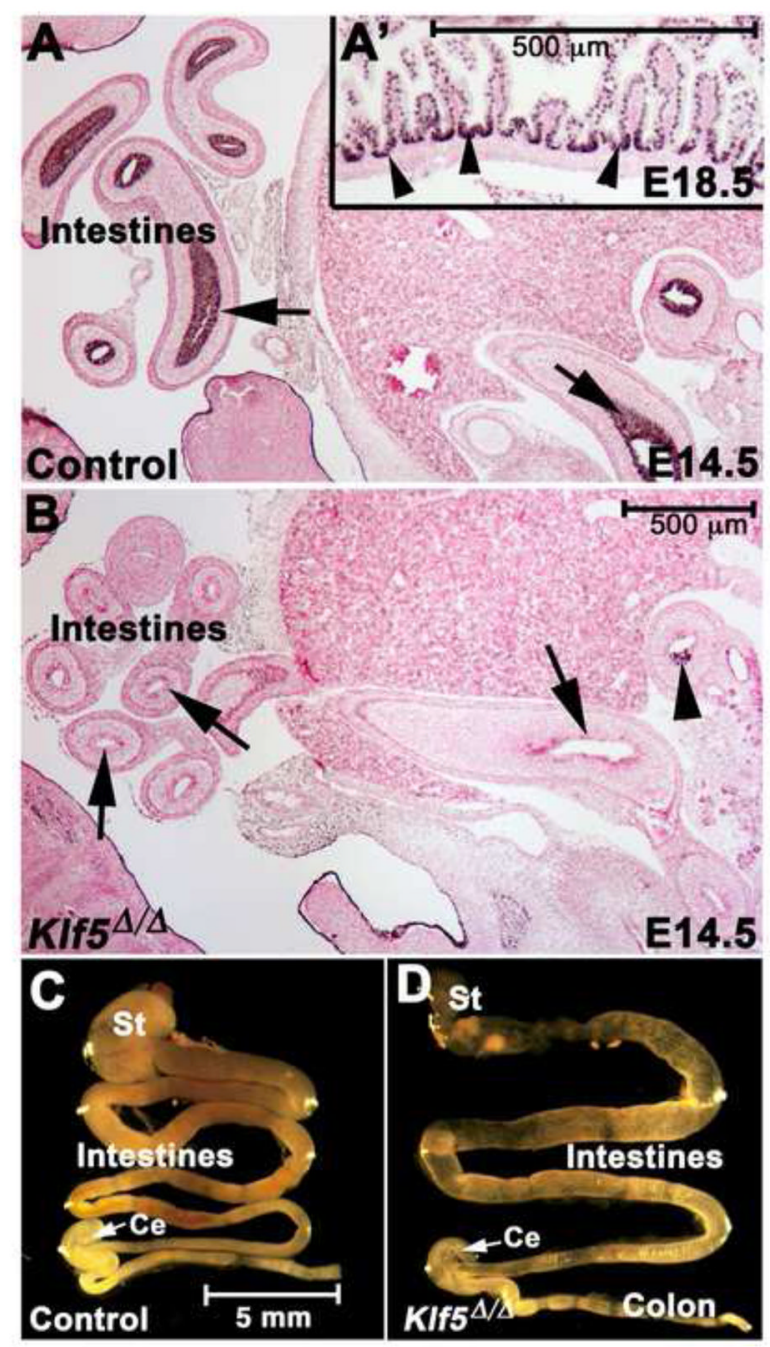

Figure 1. Efficient deletion of Klf5 from the intestinal epithelium by $S h h^{E g f p / C r e}$

KLF5 immunohistochemistry: arrows indicate the normal expression pattern throughout the intestinal epithelium in $\left(\mathrm{A}, \mathrm{A}^{\prime}\right)$ and absence of KLF5 in most of the intestine of Klf5 ${ }^{\Delta / \Delta}$ embryos (B). Inefficient recombination occurs in the duodenum (arrowhead in B). Gross appearance of the E18.5 gastrointestinal tract (C-D). In the Klf5 ${ }^{\Delta / \Delta}$ embryos, the intestinal length was decreased and the gut tube appeared more translucent and dilated. St (stomach), Ce (cecum). 


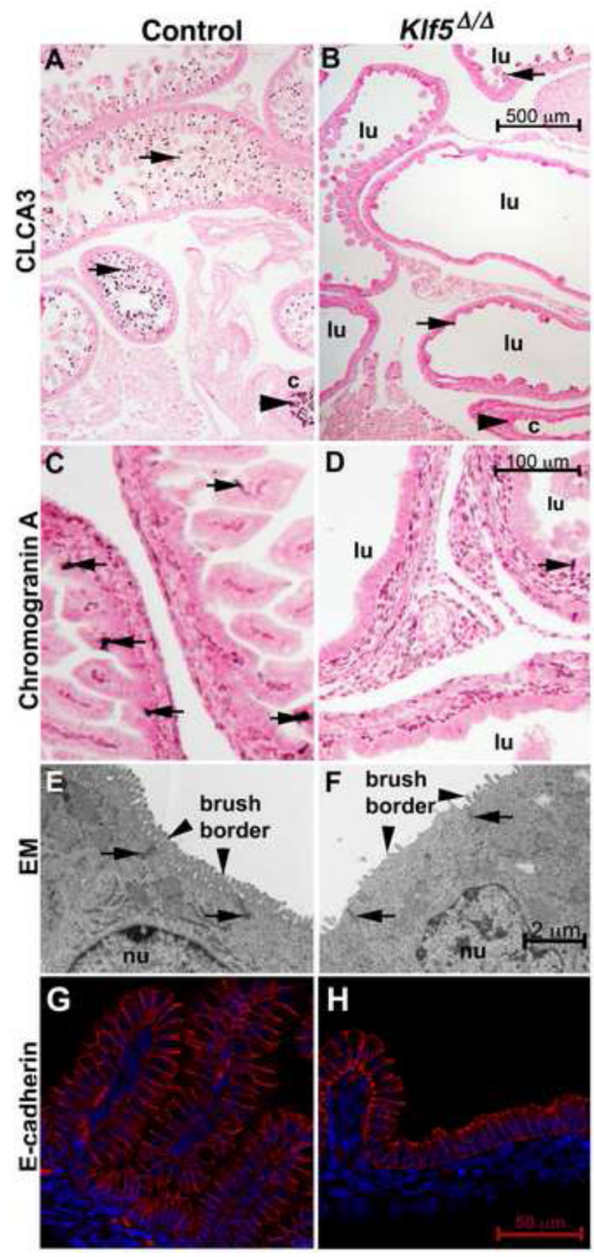

Figure 2. KLF5 is required for villus morphogenesis and epithelial differentiation

At E18.5, the goblet cell marker CLCA3 stained goblet cells on the villi of the small intestine (arrows in A) and within the colon of control fetuses (arrowhead). Villus-like structures were rarely observed in the KIf5 ${ }^{\Delta / \Delta}$ epithelium (B) and few goblet cells were present in either the intestine (B, arrows) or colon (arrowhead). Chromogranin A positive staining enteroendocrine cells were present in controls (C, arrows) but rare in the Klf5 $5^{\Delta / \Delta}$ tissue (D, arrows). The enterocyte brush border was abnormal in the $K l f 5^{\Delta / \Delta}$ epithelium (E, vs. F, arrowheads) as assessed by transmission electron microscopy. The location of tight junctions was similar in both tissues (E, F arrows). E-cadherin staining indicates that like the control $(\mathrm{G})$ the epithelium lining the $K l f 5^{\Delta / \Delta}(\mathrm{H})$ intestine was of columnar morphology on the flattened regions and on the rudimentary villus-like structures. Lumen of intestine (lu), colon (c), nucleus (nu). Scale bars for each stain are present in the $K 1 f 5^{\Delta / \Delta}$ image. 


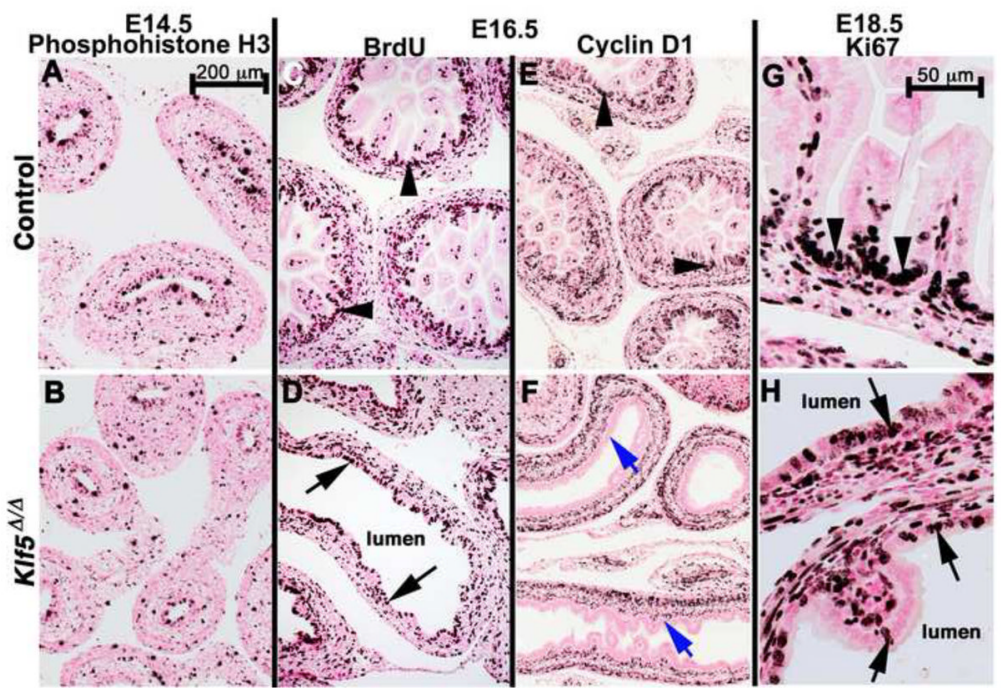

Figure 3. Proliferation continues in the absence of KLF5

Proliferating cells were identified by immunohistochemical staining for phospho-histone H3 (A-B), bromodeoxyuridine (Brdu) $(\mathrm{C}-\mathrm{D})$, cyclin D1 $(\mathrm{E})$, or Ki67 $(\mathrm{G}-\mathrm{H})$ at the indicated ages, $n \geq 3$ embryos per age and genotype. Similar levels of proliferation were observed within the epithelium and mesenchyme of control and $K l f 5^{\Delta / \Delta}$ embryos at each time point. Cyclin D1 was detected in the mesenchyme and intervillus regions of controls $(\mathrm{C}$, arrowheads) but was absent in the $K I f 5^{\Delta / \Delta}$ epithelium (C, blue arrows). Epithelial proliferation was restricted to the intervillus region in control epithelium $(\mathrm{C}, \mathrm{G}$, arrowheads) but was present throughout the $K l f 5^{\Delta / \Delta}$ epithelium (D, H, arrows). Scale bar in A is for images A-F. Scale bar in $\mathrm{G}$ is for $\mathrm{G}-\mathrm{H}$. 


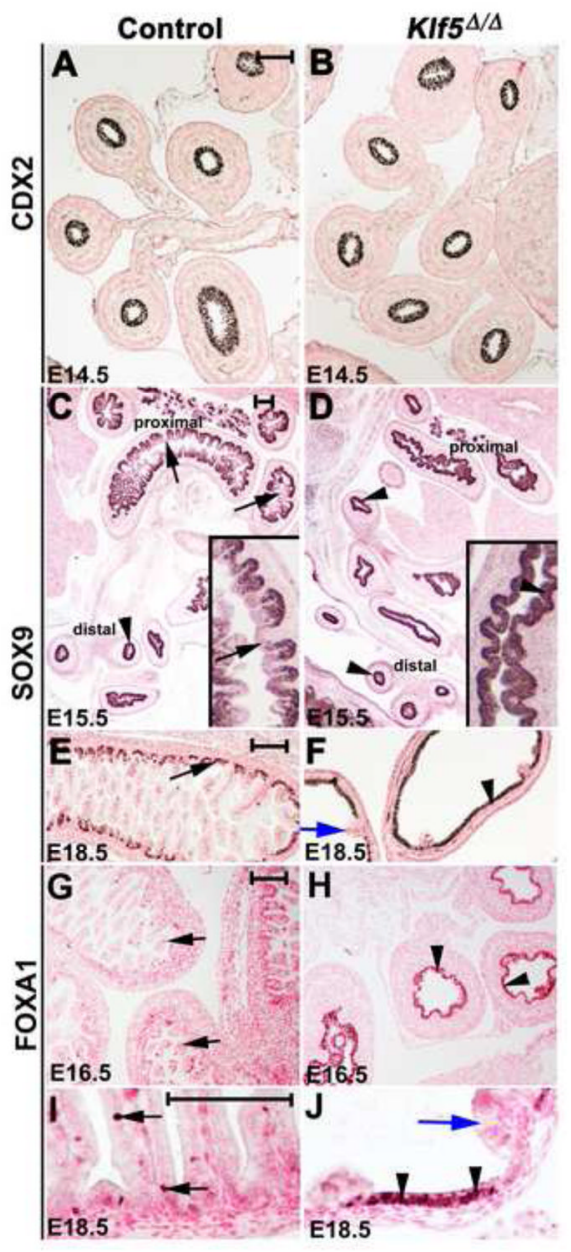

Figure 4. KLF5 is required for villus emergence at E15.5

At E14.5 a pseudostratified intestinal epithelium was present in control and $K 1 f 5^{\Delta / \Delta}$ embryos that uniformly expressed $\operatorname{CDX} 2$ (A, B). At E15.5, villi are forming in proximal regions of control fetuses accompanied by a down regulation of SOX9 at the villus tips $(\mathrm{C}$, arrows inset). Uniform SOX9 expression was present in distal regions of the intestine (C, arrowhead). SOX9 was uniform throughout the intestine of $K l f 5^{\Delta / \Delta}$ embryos (D, arrowheads). At E16.5, defined villi were present in controls where FOXA1 was localized to a subset of villus cells (G, arrows). Villi were absent within epithelium of $K 1 f 5^{\Delta / \Delta}$ embryos and FOXA1 staining was present throughout the epithelium $(\mathrm{H}$, arrowheads). At E18.5 SOX9 (E, arrows) and FOXA1 (I, arrows) expression were restricted in controls and both were expressed at high levels in the flattened epithelium of KIf $^{\Delta / \Delta}$ fetuses (F, J, arrowheads) but absent in the rare villus-like structures (blue arrows, F and J). Scale bars for each pair of images represent $100 \mu \mathrm{m}$. 


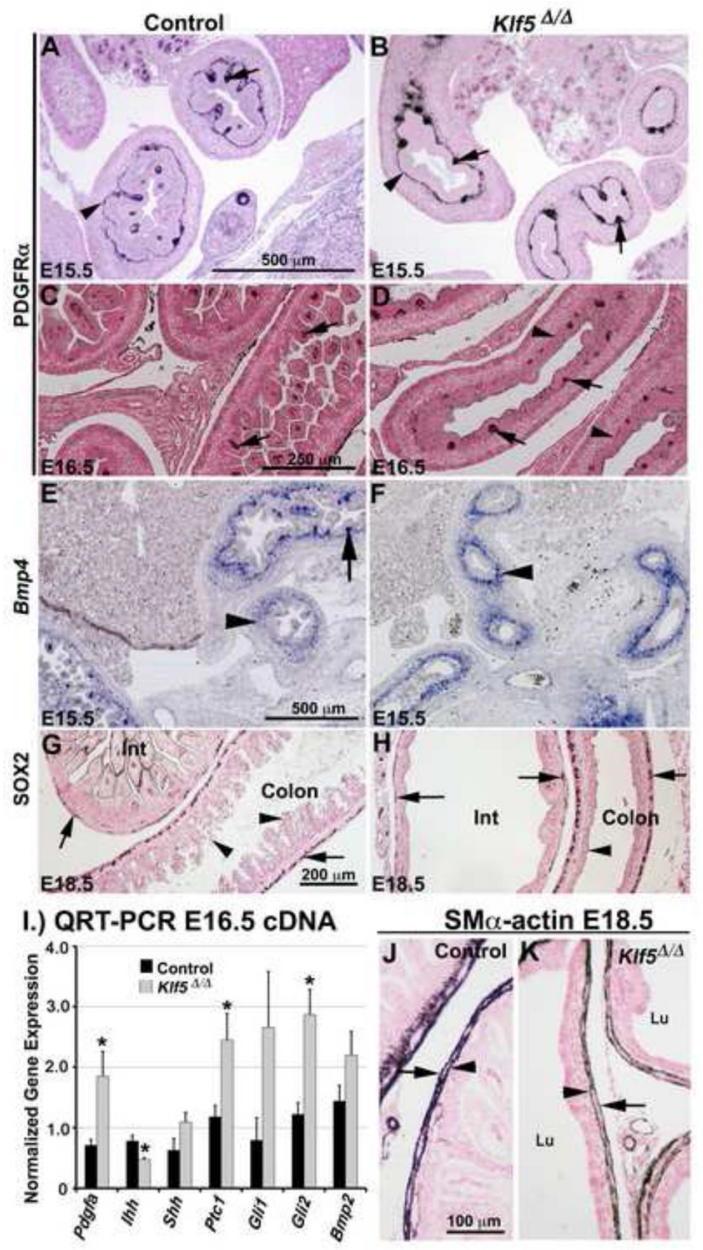

Figure 5. KLF5 regulates villus morphogenesis

In control and $K l f 5^{\Delta / \Delta}$ E15.5 embryos, immunohistochemistry detected PDGFRa in the mesenchyme in a thin line of cells subjacent to the epithelium (arrowheads, A, B) and in mesenchymal cell clusters within proximal regions of the small intestine (arrows). By E16.5, PDGFRa staining was detected in the tips of formed villi throughout the small intestine in controls (C, arrows). Although some mesenchymal clusters expressing PDGFRa were observed in distal regions of the $K l f 5^{\Lambda / \Delta}$ intestine (D, arrows) elongated villi were absent and clusters of PDGFRa expressing cells were not associated with flattened regions of the epithelium (D, arrowheads). Bmp4 mRNA was present within the subepithelial mesenchyme in both the control and KIf5 $5^{\Delta / \Delta}$ intestine (E, F, arrowheads). Note absence of forming villi in $K I f 5^{\Delta / \Delta}$ embryos compared to controls. SOX2 was detected within the mesenchyme of the intestine (Int) and colon in both genotypes ( $\mathrm{G}, \mathrm{H}$, arrows). Morphogenesis of the colon epithelium was perturbed in $K I f 5^{\Delta / \Delta}$ embryos (G vs. H, arrowheads). Significant differences in Pdgfa $(P \leq 03)$, Ihh $(P<.02)$, Ptc1 $(P<.03)$, and Gli2 $(P \leq 007)$ mRNAs were detected by QRT-PCR, $n=5$ per genotype (I). aSMA detected an outer (arrow) and inner (arrowhead) muscle layer in the mesenchyme of $K l f 5^{\Lambda / \Delta}$ and control embryos (J, K). Lu (lumen). 


\section{A) Heatmap of differentially expressed genes at E14.5}

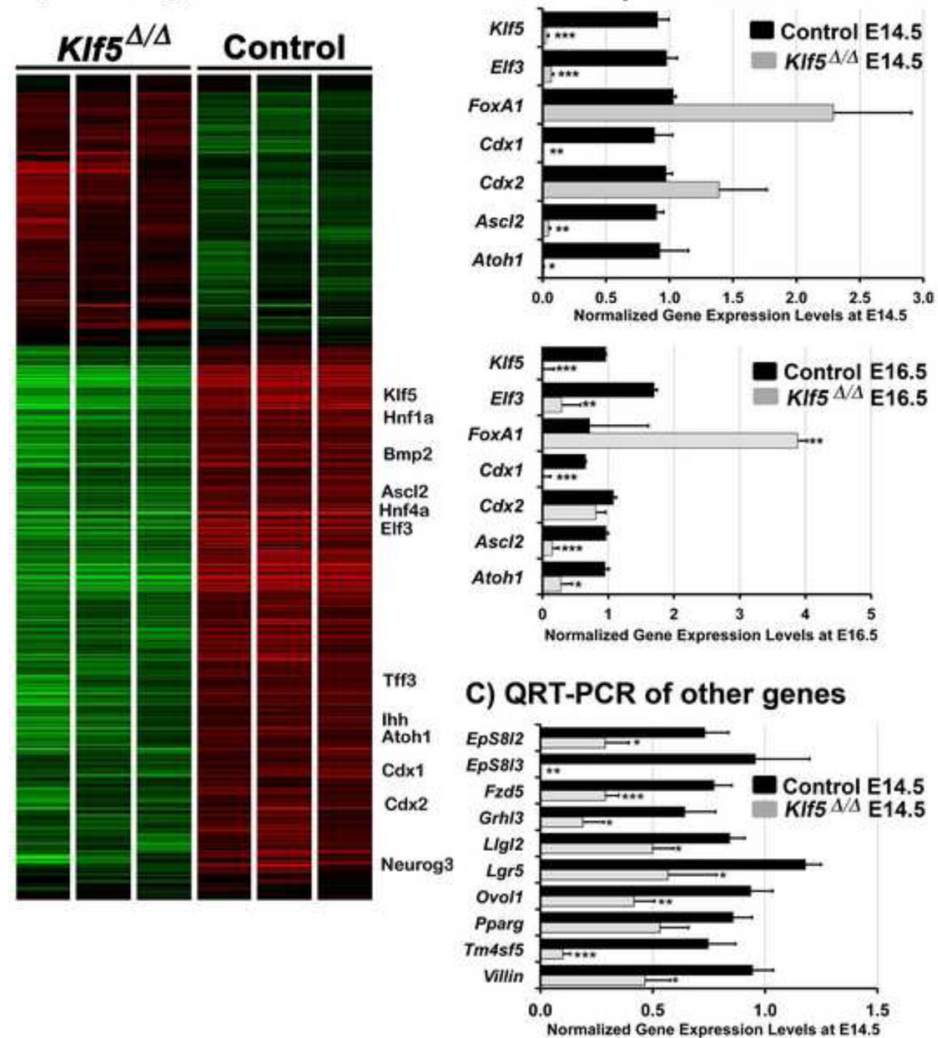

Figure 6. Transcriptome analysis in KLF5 deficient intestines

Heat map of all genes differentially expressed between $K l f 5^{\Delta / \Delta}$ and control intestines in which mRNA expression changed $>1.5$ fold with $\mathrm{P} \geq .05$. Green indicates the presence of a lower level of mRNA (A). QRT-PCR analysis of key transcription factors known to mediate terminal differentiation of epithelial cells at E14.5 and E16.5 (*, $P \leq 006),(* *, P \leq .001)(* * *$, $P \leq 0005)(B)$. QRT-PCR of E14.5 intestines also confirmed differential expression of signaling molecules and structural proteins associated with terminal maturation $(*, P \leq .04)$ $(* *, \mathrm{P} \leq .01)(* * *, P \leq 005)(\mathrm{C})$. For QRT-PCR, the two-tailed student T-test was used to assess statistical differences, $(\mathrm{n}=5$ at $\mathrm{E} 16.5 ; \mathrm{n}=4$ at $\mathrm{E} 14.5)$. 
A) Genetic network of intestine

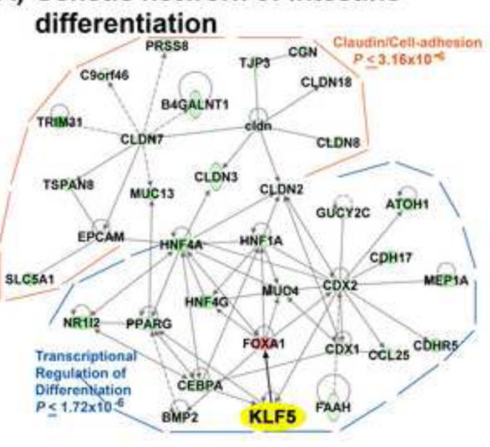

B) Regulation of the FoxA1 promoter

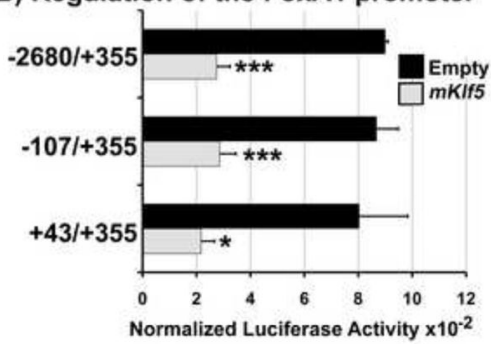

C) Regulation of the Elf3 promoter

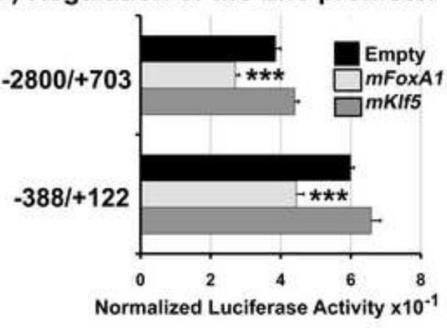

Figure 7. Identification and characterization of intestinal transcription networks regulated by KLF5

Ingenuity Pathway Analysis of the differentially expressed genes within the microarray identified gene networks functionally enriched in "transcriptional regulation of cell differentiation and "cell adhesion" (A). Solid lines (direct interactions), dashed lines (indirect interactions). B-C) Representative transient transfection assays of HEK293T cells. Luciferase activity was normalized to Renilla activity 24 hours post transfection. For all experiments, empty vector was pcDNA3.1. KLF5 over-expression inhibited all $m F O x A 1$ promoter constructs containing the region $+43 /+355$ (B). FOXA1 expression repressed both mElf3 promoter pGL3 luciferase constructs, whereas KLF5 had no effect(C). FOXA1 expression was confirmed by Western blot analysis (data not shown). The two-tailed student T-test was used to assess statistical differences ( $*, P \leq 03),(* * *, P \leq 005)$. 